Vol. 5, n`2| 2001

Varia

\title{
Paul Jankowski, Cette vilaine affaire Stavisky; histoire d'un scandale politique
}

Paris, Fayard, 2000, 467 p. (traduit de l'anglais par Patrick Hersant), ISBN 2-213-60645-5

Jean-Marc Berlière

\section{(2) OpenEdition}

\section{Journals}

Édition électronique

URL : https://journals.openedition.org/chs/753

DOI : $10.4000 /$ chs.753

ISSN : 1663-4837

Éditeur

Librairie Droz

Édition imprimée

Date de publication : 1 janvier 2001

Pagination : 166-167

ISBN : 2-600-00664-8

ISSN : 1422-0857

Référence électronique

Jean-Marc Berlière, "Paul Jankowski, Cette vilaine affaire Stavisky; histoire d'un scandale politique »,

Crime, Histoire \& Sociétés / Crime, History \& Societies [En ligne], Vol. 5, n² | 2001, mis en ligne le 02 avril 2009, consulté le 23 mars 2022. URL : http://journals.openedition.org/chs/753 ; DOI : https://doi.org/ $10.4000 /$ chs.753 
Paul Jankowski, Cette vilaine affaire Stavisky; histoire d'un scandale politique, Paris, Fayard, 2000, 467 p. (traduit de l'anglais par Patrick Hersant), ISBN 2-213-60645-5

Paul Jankowski, historien américain, spécialiste de la France de l'entre-deuxguerres à qui l'on devait une intéressante et bienvenue étude sur Sabiani et Marseille ${ }^{3}$, est un historien rare donc précieux.

À partir d'un travail méthodique et pionnier sur les innombrables sources se rapportant à un scandale qui ébranla la République, à commencer par des archives policières jamais exploitées, notamment celles de la Sûreté saisie par les Allemands en juillet 1940 et revenues de Moscou depuis 1993, il se livre à une reconstitution méticuleuse du milieu, des affaires, des réseaux, des étapes successives de l'ascension puis de la chute d'un escroc qui, usant de son charme et de toujours plus d'argent, se hissa vers les sommets de la République avant que le scandale et son suicide ne viennent ébranler les fondements de cette dernière.

Étudiant avec minutie et de façon quasi chirurgicale le rôle de la presse, de la magistrature, de l'administration, des finances, de la justice, de la police, du parlement, c'est à suivre l'itinéraire d'un escroc mondain, que Paul Jankowsky nous convie avec une érudition et une puissance d'évocation remarquables.

Ne serait-ce que pour ce travail exemplaire, cette mise à plat de toutes les affaires connexes - dont la mort du conseiller Prince - cet éclairage de détails jusqu'alors obscurcis par les passions ou l'imprécision des recherches, le livre de ce fin connaisseur de la France des années trente est à lire absolument.

Mais, écrit dans une langue superbe et un style de grande qualité (travail exemplaire du traducteur), l'ouvrage dépasse la simple étude d'un moment certes essentiel à la fois dans la mise en question de la République, dans l'exaltation des passions antisémites et la genèse de ce qui constituera Vichy, pour s'interroger sur le fonctionnement - les dysfonctionnements? - d'une République, à travers le regard et l'histoire de ceux qui ont connu, croisé l'escroc.

C'est donc aux mours et aux dérives de la $\mathrm{III}^{e}$ République, de ses magistrats, de ses députés, de ses fonctionnaires, de ses journalistes, de ses avocats, de ses élites que l'auteur, qui a décidé de «montrer plus que juger, décrire plus qu'expliquer», s'attache. Ce faisant, il peint le tableau passionnant d'une époque et d'un régime dont le « beau Serge » serait en quelque sorte le révélateur.

Dans une perspective qui n'évite pas toujours totalement la téléologie - seul travers de cette étude - Paul Jankowski montre comment un escroc habile ${ }^{4}$ sut mettre à profit toutes les contradictions et les failles nées du mariage de raison entre deux légitimités - l'administration et la Chambre - dont les compromis subtils, les concessions mutuelles, le mépris et la méfiance réciproques, paralysaient les instances de contrôle et de régulation. Dans ce « régime d'idéaux universels et d'arrangements particuliers $»$, les députés multipliaient les abus de pouvoir, tandis que l'administration sacrifiait son autonomie pour maintenir son rang...

Les représentants de cette république, ses fonctionnaires et ses riches notables, tous unis par le jeu commun des influences, omettaient souvent de distinguer entre

3 Communism and collaboration: Simon Sabiani and politics in Marseille (1919-1944), Yale University Press, 1989.

4 Quoique Stavisky profita sans doute davantage du système qu'il n'en comprit et n'en analysa les faiblesses et les incohérences. 
leurs statuts respectifs, échangeaient leurs rôles ou refusaient de s'y tenir... Ces confusions paralysaient la justice, la crainte de la concentration des pouvoirs entravait le jeu des instances régulatrices...

Si les policiers firent plutôt bien leur travail, qui percèrent à jour l'extravagant Alexandre, au Palais de Justice, aux ministères du Commerce, des Finances, les nommés se pliaient devant les élus, et, à Bayonne comme à Orléans ou à Paris, la puissance de la fonction élective sut mettre un terme aux tressaillements ou timides velléités de la justice.

Entre le «député-roi », futur ou ancien ministre, l'avocat-député, futur ou ancien garde des Sceaux, une presse dont la puissance ne fait ressortir que plus vivement le manque de moyens et qui n'hésite pas à user du chantage pour se procurer l'argent qui lui manque, des banquiers et assureurs dupes ou complices, des ministres aveugles ou incompétents, le tableau que dresse Paul Jankowski paraît - mais le détail des escroqueries de Stavisky, comme de son incroyable impunité peuvent justifier une telle lecture - à la limite de la caricature.

Décidément cette III ${ }^{\mathrm{e}}$ République avait plus de défauts que les hommes de Vichy, de Gaulle et les résistants réunis n'en pourraient dénoncer les années suivantes. Le scandale Stavisky permet d'observer comment une société, aveugle à ses propres travers, se tourna contre l'État et ses officiers ou ses représentants. On ne s'étonne pas qu'il se soit trouvé si peu de parlementaires pour prendre le risque de défendre un tel régime le 10 juillet 1940.

Carriérisme, cumuls de fonctions, jeux d'influence mis en lumière par les enquêtes et les péripéties de l'affaire sont pourtant bien banals et sembleraient anodins par rapport à d'autres affaires plus contemporaines. Un scandale financier somme toute moins grave que celui du Panama, une affaire à tout prendre moins dramatique que l'affaire Dreyfus, permet la mise au jour d'une «éthique et de ses blessures». Au delà de ce nouvel épisode des liaisons dangereuses entre l'argent et la démocratie, Paul Jankowsky se veut optimiste: «si les pratiques de la République en contredisent les idéaux, notamment dans le domaine hautement symbolique de la justice, la ténacité de l'idéal collectif fait naître une attention scrupuleuse, un sens de l'indignation et un violent désir de justice».

Même si on ne suit pas l'auteur dans ses thèses et conclusions, on lit ce livre comme un roman, non seulement parce que le sujet s'y prête, mais parce qu'il est servi par une mise en scène des sources d'une aisance et d'une élégance rares.

Jean-Marc Berlière Université de Bourgogne, Dijon, France berliere@alcyone.u-bourgogne.fr

\section{David W. Howell and Kenneth O. Morgan (eds.), Crime, Protest and Police in Modern British Society: Essays in Memory of David J. V. Jones (University of Wales Press, Cardiff, 1999), $x+248$ pp., ISBN 0-7083-1555-0}

It immediately emerges from this edited collection of essays that David Jones was a widely respected historian, colleague and teacher. His early death was shocking, yet the decision to publish an edited volume of essays dedicated to Jones' contributions to social history can be applauded. He was an influential scholar 